ISSN: 0213-2060

DOI: https://doi.org/10.14201/shhme20203815980

\title{
LA QIBLA EN LA CASTILLA MEDIEVAL ${ }^{1}$
}

\section{The qibla in Castile in the Middle Ages}

Javier JIMÉNEZ GADEA

Museo de Ávila. Plaza de Nalvillos, 3. E-05001 ÁVILA. C. e.: javier.jimenezgadea@jcyl.es

Recibido: 2019-11-16

Revisado: 2020-03-10

Aceptado: 2020-05-04

RESUMEN: Se aborda en este trabajo un acercamiento a la cuestión de la orientación de la quibla entre los musulmanes castellanos de la cuenca del Duero en la Plena y la Baja Edad Media. No se pretende realizar con ello una nueva disquisición sobre la qibla peninsular (estudiada únicamente para el caso andalusí), sino proponer un nuevo acercamiento al islam medieval del valle del Duero, para valorar en qué medida esta cuestión afectó a los musulmanes castellanos y en qué medida, asimismo, este análisis histórico nos puede ayudar a conocer su grado de islamización y su relación con el resto del islam peninsular.

Palabras clave: Castilla; La Meca; Islam; Quibla; Mezquitas; Cementerios.

ABSTRACT: This paper addresses an approach to the question of the orientation of the quibla among the Castilian Muslims of the Duero basin, in the Middle Ages. It is not intended to make a new disquisition about the peninsular qibla (studied only for alAndalus), but to propose a new approach to the medieval Islam of the Duero Valley, in order to assess to what extent this issue affected the Castilian Muslims and to what extent this historical analysis can help us to know its degree of Islamization and its relationship with the rest of peninsular Islam.

Keywords: Castile; Mecca; Islam; Qibla; Mosques; Cemeteries.

SUMARIO. 0 Introducción. 1 Al-Andalus. 2 El islam castellano. 2.1 Cementerios. 2.2 Mezquitas. 3 Valoración. 4 Referencias bibliográficas.

1 Trabajo escrito en el marco del Proyecto de Investigación I+D HAR2017-83004-P, Estudio de los espacios rituales mudéjares en la Castilla medieval: mezquitas y cementerios islámicos en una sociedad cristiana (IP Olatz Villanueva Zubizarreta). 


\title{
0 INTRODUCCIÓN
}

El muro de las mezquitas hacia el que los fieles dirigen la oración se conoce con el nombre de quibla ${ }^{2}$. En su parte central se ubica el mihrab, lugar destacado con algún recurso arquitectónico o decorativo que sirve de referencia y define sin ningún género de dudas cuál es el muro de la quibla en el templo. Dirigiendo la oración hacia él, el creyente se estará dirigiendo hacia La Meca, más concretamente hacia la $\mathrm{Ka}$ ` $\mathrm{ba}$.

Pero la quibla, en realidad, no es el muro, sino la dirección. Dirección fijada por revelación de Dios al profeta Muhammad y recogida así en el Corán:

\begin{abstract}
Vemos cómo vuelves tu rostro hacia el cielo. Haremos, pues, que te vuelvas hacia una dirección que te satisfaga. Vuelve tu rostro hacia la Mezquita Sagrada. Donde quiera que estéis, volved vuestro rostro hacia ella ${ }^{3}$.

Vengas de donde vengas, vuelve tu rostro hacia la Mezquita Sagrada. Esta es la Verdad que viene de tu Señor. Dios está atento a lo que hacéis. // Vengas de donde vengas, vuelve tu rostro hacia la Mezquita Sagrada. Estéis donde estéis, volved vuestros rostros hacia ella, de modo que nadie, excepto los que hayan obrado impiamente, pueda alegar nada contra vosotros. Y quizá, así, seáis bien dirigidos ${ }^{4}$.
\end{abstract}

El seguimiento de la quibla, pues, es un mandato coránico. Dirección que no solo debe seguirse en la oración, sino que en el islam representa una referencia continua que debe presidir y regular muchos otros actos de la vida religiosa y diaria ( $d u$ ' $\vec{a}$, ihla $l$, ihr rām, sacrificio de animales o las necesidades fisiológicas, por ejemplo), así como de las prácticas funerarias, según transmiten numerosos ḥadît $(\mathrm{es})^{5}$.

Por lo tanto, cuando como consecuencia de la expansión del islam, a partir de la segunda mitad del siglo viI, se fueron estableciendo comunidades musulmanas cada vez más alejadas de los lugares nucleares de la religión -La Meca y Medina-, la determinación de la qibla, el punto hacia el que los fieles debían orientar sus prácticas religiosas, devino en una cuestión crucial, ya que de ello dependía el cumplimiento de un mandato

2 Del árabe قبلة qibla, que ha originado las palabras castellanas sinónimas quibla y alquibla. Se utilizarán en este trabajo indistintamente, aunque se preferirá qibla para el contexto andalusí y para su significado de «dirección»; alquibla para el contexto castellano bajomedieval; y quibla para un contexto más genérico.

3 Corán, 2, 144. En esta y en posteriores citas se seguirá la edición española de El Corán, ed. Julio Cortés. 8. ${ }^{\mathrm{a}}$ ed. Barcelona: Herder, 2002. La Mezquita Sagrada es la $\mathrm{Ka}$ ‘ ba.

4 Corán, 2, 149-150.

5 Véase Wensinck, Arent Jan. «Kibla. I». En Bosworth, Clifford E.; Van Donzel, Emeri J.; Lewis, Bernard y Pellat, Charles (eds.). Encyclopédie de l'Islam. Nouvelle édition. Leyden-Paris: Brill-Maisonneuve \& Larose, 1986, t. V, pp. 84-85, p. 84. También en actos de supersticiones populares, como pedir lluvia: Yahya me relató de Malik, de Abdallah Ibn Abu Bakr Ibn Amr Ibn Hazim, que él habia oido a Abbad Ibn Tamim decir que él habia oído a Abdallah Ibn Zayd al-Mazini decir: "El Mensajero de Allah, que Allah le bendiga y le conceda paz, salió al lugar de la oración y pidió la lluvia, y, dando la cara a la Qibla, se puso la capa del revés», según un hadìt recogido por Mālik ibn Annas (MāLık ibn Anas. Al-Muwațta, trad. Abdurrasak Pérez, Iman Puch. Almodóvar del Río: Junta Islámica, Centro de Documentación y Publicaciones Islámicas, 1999, p. 105). 
coránico y su definición como comunidad (abl al-qibla) diferenciada de judíos y cristianos $^{6}$.

Sin embargo, el conocimiento (geográfico, matemático y astronómico) desarrollado que permitiera fijar con relativo acierto la posición de La Meca, con respecto a lugares muy alejados de ella tanto en latitud como en longitud, no se produjo en el mundo islámico hasta el siglo $\mathrm{x}$. La consecuencia es que las primeras mezquitas alejadas de la zona nuclear del islam, tanto en el Magrib como en Iraq, presentan una quibla desviada hacia el sur con respecto a la dirección real de La Meca tomada con métodos actuales. Esta misma circunstancia afectó a las mezquitas de al-Andalus, hecho que no constituye, pues, una excepción o una circunstancia propia de las mezquitas peninsulares.

Con ello, dos de las grandes mezquitas de los primeros tiempos del islam en Occidente, las mezquitas aljamas de Cairuán (siglo vir d. C) y de Córdoba (siglo viII d. C), que sirvieron de referencia y modelo para muchas otras, presentan una orientación que realmente no se dirige con exactitud hacia la $\mathrm{Ka}^{ } \mathrm{ba} \mathrm{a}^{7}$.

De estas circunstancias y de la necesidad de orientar correctamente las mezquitas ya se dieron cuenta los alfaquíes de los primeros siglos de la Hégira, por lo que, por un lado, surgió un tipo de tratados denominados Kitab al-Qibla, que eran libros expresamente dedicados al problema, y, por otro, numerosas consultas de las comunidades, que o bien eran conscientes de la orientación dudosa de sus mezquitas o bien necesitaban saberla para construir una nueva, y que se traducían en las correspondientes fatwā $(s)$ de los alfaquíes a los que las dirigían. También fue frecuente que en los libros de astronomía y matemáticas hubiera algún punto o apartado relacionado con la búsqueda o método de hallar el azimut de la Ka 'ba o la dirección de La Meca. Incluso se desarrollaron teorías basadas en una astronomía y geografía popular, en la observación directa de las estrellas y se elaboraron mapas de qibla basados en una concepción concéntrica y sagrada del mundo con epicentro en la $K a$ ' $b a$ (geografía sagrada). Con todo ello se puede decir que se forjó un verdadero y variado corpus doctrinario relacionado con el asunto, con obras fundamentalmente alto y pleno medievales, pero que llegó incluso, en el Magrib, hasta el siglo XVIII ${ }^{8}$.

6 Aun si aportas toda clase de signos a quienes han recibido la Escritura, no siguen tu alquibla, ni tú debes seguir la suya, ni siguen unos la alquibla de otros (Corán, 2, 145).

Según la tradición, la mezquita de Cairuán fue levantada en el mismo punto en el que Sidi 'Uqba ('Uqba ibn Nāfi', conquistador del Magrib en el siglo vI) hizo la primera oración antes de que existiera la propia mezquita y donde él mismo, por revelación divina, fijó el lugar en el que debía construirse el mibrab, estableciendo así la qibla de la misma (MarçaIs, George. Manuel d'Art Musulman. L'architecture. Tunisie, Algérie, Maroc, Espagne, Sicile. T. I, Du IX au XI siècle. Paris: August Picard, 1926, pp. 12-16); a su vez, y también según relatos tradicionales, la qibla de la aljama cordobesa fue establecida, en el mismo 711, por dos täbi ${ }^{\prime} u ̄ n$, discípulos de los compañeros del Profeta (Ocaña Jiménez, Manuel. «Arquitectos y mano de obra en la construcción de la Gran Mezquita de Occidente». Cuadernos de la Alhambra, 1986, vol. 22, pp. 55-85, p. 59). Sobre la presencia y papel de los täbi 'ün en la fundación de las primeras mezquitas andalusíes, véase Calvo Capilla, Susana. Las mezquitas de al-Andalus. Almería: Fundación Ibn Tufayl de Estudios Árabes, 2014, pp. 32-39.

8 Sobre los métodos de hallar la qibla y su desarrollo histórico véase KING, David A. «Kibla. II. Calcul de la Kibla». En Bosworth, Clifford E.; Van Donzel, Emeri J.; Lewis, Bernard y Pellat, Charles (eds.). Encyclopédie de l'Islam. Nouvelle édition. Leyden-Paris: Brill-Maisonneuve \& Larose, 1986, t. V, pp. 85-91. Igualmente, resultan de referencia y consulta obligada para el Magrib y al-Andalus, los trabajos de 
$\mathrm{Y}$, al tiempo, se fueron forjando dos corrientes principales para resolver el problema, basadas en dos conceptos: la $\hat{y} i h a$ y el samt $t^{9}$. La $\hat{y} i h a$ (dirección, en general) implica aceptar una orientación aproximada para la quibla, que puede moverse en un ángulo de entre $90^{\circ}$ y $180^{\circ}$ en torno a la dirección exacta. El samt (dirección exacta), por el contrario, supone aceptar únicamente esta, lo que en muchos casos, cuando se adoptó esa postura, implicó derribar las mezquitas existentes para construir otras mejor orientadas ${ }^{10}$.

Como ya ha señalado Rius ${ }^{11}$, esto debe obligarnos a plantearnos una cuestión de terminología, en el sentido de que muchas de estas mezquitas occidentales, cuya quibla se desvía acusadamente hacia el sur, no necesariamente están «mal» orientadas, ya que, si les aplicamos la $\hat{y}$ iha, se mueven la mayoría dentro de un ángulo de $90^{\circ}$ en torno a su orientación exacta, estando la mayoría dentro del cuadrante SE de la circunferencia. Factores tradicionales, religiosos, astronómicos, geográficos e incluso políticos orientaron estas primeras quiblas, pero siempre con la intención de seguir el mandato coránico de dirigirse hacia la Mezquita Sagrada.

\section{Al-Andalus}

Sabed-Dios tenga piedad de nosotros y de vosotros- que la qibla de la gente del Magrib es un asunto dificil por dos causas: la primera es que los imams que han explicado las fuentes no mencionan, en su mayoría, cómo guiarse mediante las estrellas y los ortos y ocasos del Sol (...) y los sabios de otros confines que han hablado sobre la qibla, tan sólo hablan sobre la suya (...). El segundo motivo es la diferencia que existe entre sus mezquitas. Sus edificaciones tienen entre si grandes diferencias: algunas se dirigen hacia los ortos del Sol en verano, otras se dirigen hacia el equinoccio, otras hacia los ortos del Sol en invierno y, en fin, otras hacia el pleno sur, es decir, hacia el orto de Suhayl.

Este texto de al-Mașmūdī, extraído de su Kitab al-Qibla, resulta perfectamente extrapolable a la Península Ibérica, ya que recoge tanto la multiplicidad de orientaciones existentes como la preocupación que este hecho causaba en quienes se esforzaban en buscar la qibla correcta ${ }^{12}$.

Efectivamente, también las primeras mezquitas andalusíes, y la aljama de Córdoba a la cabeza, resultaron orientadas hacia un punto meridional no coincidente con exactitud con La Meca -medido con instrumentos actuales-, como muchas otras del occidente

Rius, Mònica. «La alquibla en al-Andalus y el Magrib al-Aqșà». Anuari de Filologia. Secció B, Estudis Àrabs i Islàmics, 1998-1999, vol. 3, pp. 17-358; y Rıus, Mònica. «La alquibla: ¿ciencia religiosa o religión científica?». 'Ilu. Revista de Ciencias de las Religiones. Anejos, 2006, vol. 16, pp. 93-111.

9 KING, David A. «The Orientation of Medieval Islamic Religious Architecture and Cities». Journal of the History of Astronomy, 1995, vol. 26, n. ${ }^{\circ}$ 3, pp. 253-274, p. 259; RIUs, «La alquibla: ¿ciencia religiosa?», p. 99.

10 Sin embargo, y curiosamente, en algunos ejemplos conocidos la destrucción de una mezquita, para reconstruirla con una nueva orientación, no produjo un templo mejor orientado, caso de la Kutubìya de Marrakesh, cuya quibla está más desviada hacia el sur que su precedente.

11 Rius, «La alquibla: ¿ciencia religiosa?», p. 99.

12 Abū 'Alī Ṣăliḥ al-Mașmūdī, alfaquí magrebí del siglo xiv (Rıus, «La alquibla en al-Andalus», pp. $42-51$ y 269$)$. 
JAVIER JIMÉNEZ GADEA

islámico medieval. Pero, se insiste una vez más, se debe matizar mucho esta afirmación y evitar generalizaciones y conclusiones equivocadas, tendentes a sugerir un comportamiento andalusí individualizado sobre este tema, diferente del existente en el conjunto de la Dār al-Islām'

En primer lugar, Jiménez Martín demostró que la aljama de Córdoba no está orientada exactamente hacia el sur, como se venía repitiendo desde los primeros estudios que trataron de ella. Este autor proporciona una orientación de $169^{\circ}$, lejos del valor real de $111^{\circ}$ que le correspondería. Ciertamente hay una desviación de $58^{\circ}$, pero ciertamente también se encuentra lejos de lo que supondría una orientación plenamente sur ${ }^{14}$. Otros valores para la orientación de la qibla cordobesa se recogen en Samsó, que aporta datos de varios autores ${ }^{15}$, moviéndose entre $20^{\circ}$ y $30^{\circ}$ al este del sur (o sea, $160^{\circ} / 150^{\circ}$ ), y en Rius $^{16}$ y King ${ }^{17}, 152^{\circ}$. Pero más allá del dato concreto, lo que se puede afirmar de la qibla cordobesa es que queda dentro del cuadrante SE, más concretamente en su sector más próximo al sur (S-SE), y que, si aplicamos el concepto de ŷiha, la orientación de la mezquita es, pues, $\operatorname{correcta}^{18}$.

13 Los siguientes estudios al respecto resultan clarificadores en esta materia: SAMsó, Julio. «En torno al problema de la determinación del acimut de la alquibla en al-Andalus en los siglos viII-IX. Estado de la cuestión e hipótesis de trabajo». En Homenaje a Manuel Ocaña Jiménez. Sevilla: Junta de Andalucía, 1990, pp. 207-212; SAmsó, Julio. Las ciencias de los antiguos en al-Andalus. Madrid: Mapfre, 1992; JimÉneZ Martín, Alfonso. "La qibla extraviada». Cuadernos de Madinat al-Zahrā', 1991, vol. 3, pp. 189-209; KING, "The Orientation»; KING, David A. "The enigmatic orientation of the Great Mosque of Córdoba». Suhayl. International Journal for the History of the Exact and Natural Sciences in Islam Civilisation, 2018-2019, vol. 16-17, pp. 33-111; Rius, «La alquibla en al-Andalus»; y Rius, "La alquibla: ¿ciencia religiosa?». Para el norte de África, los de Bonine, Michael E. «The sacred direction and city structure: A preliminary analysis of the Islamic cities of Morocco». Muqarnas, 1989, vol. 7, pp. 50-72; y Bonine, Michael E. «Romans, astronomy and the qibla: urban form and orientation of Islamic cities of Tunisia». En Holbrook, Jarita C.; Medupe, Rodney Thebe y Urama, Johnson O. (eds.). African Cultural Astronomy - Current Archaeoastronomy and Ethnoastronomy Research in Africa. Berlin: Springer, 2008, pp. 145-178. Véase también Vergara-MuÑoz, Jaime y Martínez-Monedero, Miguel. "Las mezquitas de Arcila (Marruecos): mihrabs y quiblas». Miscelánea de Estudios Árabes y Hebraicos. Sección Árabe-Islam, 2018, vol. 67, pp. 227-245, como ejemplo del caso concreto de Arcila (Marruecos), donde todos los edificios religiosos estudiados presentan esta misma desviación.

14 JimÉnez Martín, «La qibla extraviada», p. 194. Debe tenerse en cuenta, no obstante, que los datos proporcionados por este autor se expresan sobre una base decimal, de un círculo dividido en 400 unidades, por lo que no son directamente comparables con mediciones basadas en $360^{\circ}$ sin hacer previamente una conversión.

15 SAmsó, Las ciencias de los antiguos, p. 61.

16 Rius, «La alquibla en al-Andalus», p. 115.

17 KING, "The enigmatic orientation».

18 La qibla moderna es de $100.3^{\circ}$. Otra cosa es determinar cómo o por qué se tomó la decisión de levantar la mezquita con esa dirección. La búsqueda del orto de la estrella Suhayl (Canopo) o del Sol en el solsticio de verano pueden haber servido como referencia para los ejes mayor y menor respectivamente del templo. Curiosamente, esta disposición resulta paralela a la de la $\mathrm{Ka}$ ` $\mathrm{ba}$, por lo que David A. King desarrolló la teoría de que la aljama cordobesa pudo haber buscado conscientemente una orientación igual a esta, ya que de esa manera, además, los fieles de Córdoba se dirigirían en su oración hacia la esquina del templo mecano asignada a al-Andalus, según la distribución, basada en la geografía sagrada, por la que a cada región del islam se le atribuye un sector de la $K a$ 'ba (KING, "The Orientation»). Recientemente, el autor ha vuelto sobre la cuestión (KING, "The enigmatic orientation»), en una necesaria actualización que recoge también los datos de las excavaciones arqueológicas realizadas en Córdoba en los últimos veinte años, analizando el dato de la 
Si observamos la tabla proporcionada por Alfonso Jiménez en su trabajo, que contiene las orientaciones de un buen número de mezquitas andalusíes ${ }^{19}$, se puede observar que claramente hay un grupo reducido de ellas -ocho- cuya orientación se aproxima bastante a los valores exactos, desviándose una media de solo $15^{\circ}$. Este grupo tiene el común denominador -salvo los casos de las mezquitas de Madīnat al-Zahra y Santa Clara de Córdoba- de su cronología, siglo xiv, y ubicación en el territorio del reino nazarí. La de Madinat al-Zahra comparte con algunas de estas -las de la Alhambra-, por otro lado, el hecho de pertenecer a un conjunto palatino.

Se mezclan, pues, dos circunstancias. Por un lado, cuando la erección de la mezquita se debió directamente a un encargo real y para un uso exclusivo y reducido a la corte, parece que hubo un interés especial en utilizar el criterio del samt, del iŷtihād-esfuerzo- en conseguir la mejor orientación posible ${ }^{20}$. Y, por otro lado, que cuanto más tardías fueron estas mezquitas, existían al tiempo más y mejores mecanismos y referencias para orientar los templos.

Efectivamente, en época nazarí se disponía ya de un buen conocimiento científico que permitía edificar mezquitas de la mejor manera posible acercándose a la dirección exacta, y hubo además un interés especial en ello $^{21}$. No obstante, debe observarse cómo en Granada estas mezquitas cuya orientación queda en un sector E-SE (entre 90 y 125) corresponden básicamente a las de la Alhambra, mientras que la aljama de la ciudad y otras se sitúan fundamentalmente en el sector S-SE (entre $135^{\circ}$ y $\left.180^{\circ}\right)^{22}$.

Al-Andalus, pues, vivió de lleno este dilema sobre la orientación de la quibla. Aunque no se ha conservado ningún tratado de qibla andalusí2 ${ }^{23}$, sabemos, sin embargo, que tanto alfaquíes como hombres de ciencia se ocuparon de la cuestión por referencias en otro tipo de libros y por noticias sobre debates y discusiones entre los alfaquíes sobre el tema ${ }^{24}$.

coincidencia del edificio con el preexistente trazado viario de la ciudad romana, desde la óptica de la alineación solsticial de este, y desmontando de nuevo las interpretaciones que insisten en la copia de modelos sirios para la orientación de la aljama cordobesa o en el simple condicionante de la topografía urbana preexistente. Este trabajo supone el acercamiento más reciente a la cuestión.

19 Ochenta y dos, concretamente (Jiménez Martín, «La qibla extraviada», p. 194). Para los datos y circunstancias histórico-cronológicas de estas y del resto de las andalusíes, véase Calvo Capilla, Las mezquitas de al-Andalus.

20 Sobre la excepcionalidad de las mezquitas palatinas, Calvo Capilla, Las mezquitas de al-Andalus, pp. 487-488. La de Madinat al-Zahra se consideró en la época la mezquita mejor orientada durante mucho tiempo. Sin embargo, en el mismo siglo x y ciudad, cuando el califa al-Hakam II llevó a cabo la segunda ampliación de la aljama cordobesa y surgió la necesidad de decidir si se reorientaba su quibla, para hacerla coincidir con la de la ciudad palatina, se tomó la decisión de no hacerlo y mantener la dirección preexistente, tras la consulta realizada al alfaquí Abū Ibrahim, quien dictaminó que debía mantenerse por respeto a la tradición: "El que sigue la tradición acierta; fracasa el que se entrega a las novedades», dijo (Torres Balbás, Leopoldo. «Arte califal». En Historia de España Menéndez Pidal. Vol. 5, España musulmana: hasta la caída del califato de Córdoba (711-1031 de J. C.). Madrid: Espasa Calpe, 1957 (4. ${ }^{\mathrm{a}}$ ed. 1982), p. 478, tomado de al-Maqqārī).

21 Samsó, Las ciencias de los antiguos, pp. 412-420.

22 Jiménez Martín, «La qibla extraviada», p. 194; Rius, «La alquibla en al-Andalus», pp. 110-120, donde se transportan a grados sexagesimales los datos del anterior, lo que permite su más fácil manejo y análisis.

23 Con alguna excepción dudosa reseñada por Rius, «La alquibla en al-Andalus», p. 172.

24 Sobre muwaqqit(s) (expertos en la medición del tiempo a través de las estrellas y el sol, para la determinación de las horas de rezo, del creciente lunar o de la qibla) andalusíes, ver Rius, «La alquibla: ¿̨ciencia 
En este sentido, resulta especialmente interesante, por su repercusión entre los tratadistas del tema, la disputa mantenida entre el muwaqqit Abū-l-Hasan 'Alī ibn Mūsà ibn 'Ubayd Allāh al-Lajmī al-Qarabāqī (m. 1440), de Baza, y Abū-l-Qāsim ibn Sirāŷ (1444), imām y muftí de Granada, sobre la marcada desviación hacia el sur de muchas mezquitas andalusíes, asunto aún vivo en el siglo xv. El primero defendía que debía practicarse el $i \hat{y} t i h \bar{a} d$ para conseguir una orientación precisa, mientras que el muftí granadino era partidario de una dirección a cualquier punto del cuadrante SE, lo que permitía al creyente practicar el taqlìdo imitación de cualquier mezquita construida con anterioridad. La disputa fue recogida por los juristas magrebíes Abū-l-'Abbās Aḥmad ibn Yaḥyà al-Wanšarisī (siglo xv) y Muhammad al-Fāsī (siglo XviıI) ${ }^{25}$.

En parte la disputa venía acentuada porque, como ya se ha dicho, en el siglo XIV se habían desarrollado bastante los métodos para conseguir orientaciones más ajustadas a la realidad. El primer tratadista andalusí que halló una qibla exacta astronómica fue Ibn Mu'ād al-Ŷahyyānī (m. 1093), quien, en sus Tablas de Jaén, ya dio la primera solución exacta documentada en al-Andalus para el establecimiento de la quibla, basándose en un método astronómico ${ }^{26}$. Pero la solución matemática final del problema fue la tabla realizada en el siglo xIv por el astrónomo sirio Šams al-Dīn al-Jalîlī ${ }^{27}$.

A pesar de ello, en al-Andalus, como en el resto de la Dār al-Islām, siguieron teniendo mucho peso las opiniones de alfaquíes sustentadas en la tradición y los recursos basados en métodos populares para determinar la qibla ${ }^{28}$, lo que redundó en un predominio del criterio $\hat{y} i h a$. Por otro lado, este era el defendido por Malik ibn Anas, fundador de la escuela jurídica maliki seguida en al-Andalus ${ }^{29}$; y había entre los alfaquíes malikies una preferencia por la astronomía popular, frente a los métodos matemáticos.

La realidad es que en al-Andalus encontramos quiblas de todos los tipos. Mientras que la Rábita de Guardamar (Alicante) nos ofrece un buen ejemplo claro de $\hat{y} i h a$, ya que los diferentes oratorios allí existentes, fechados entre los siglos IX-XI, se dirigen, genéricamente y como tendencia general, al sur, sin ser coincidentes entre ellos, con valores que van desde los $160^{\circ}$ hasta los $206^{\circ}-y$ sin que esto parezca haber creado ningún problema a la comunidad allí establecida-, se puede apreciar, al tiempo, que en el siglo XIV, de las nueve mezquitas nazaríes medidas por Jiménez Martín, solo tres dirigen sus quiblas con una tendencia sur, quedando las restantes dentro del sector E-SE, muy próximo a la dirección exacta.

religiosa?”, pp. 95-96, donde se destaca fundamentalmente a Abū 'Alī al-Hasan al-Qurțubī (siglo XII) y a los Banu Bāṣo granadinos, ya en el xIv. También el toledano Abū 'Ubayda Muslim ibn Aḥmad al-Laytī (siglo Ix), del que el cadí Șāi id de Toledo decía que tenía conocimientos de astronomía y al que llamaban șāhib al-qibla (SAmsó, Las ciencias de los antiguos, pp. 60 y 79), que defendía para al-Andalus la orientación hacia el este.

25 SAmsó, Las ciencias de los antiguos, p. 413; y Rius, «La alquibla en al-Andalus», pp. 173-174.

26 SAmsó, Las ciencias de los antiguos, pp. 161-166.

27 KING, «The Orientation», p. 261.

28 Lograrás la qibla, en al-Andalus, colocando el Polo en el hombro izquierdo y dirigiéndote, luego, hacia el sur. Donde quede tu vista, será la qibla, según al-Umāwī al-Qurțubī (m. 1205) (RıUs, "La alquibla en alAndalus», p. 181).

29 Según Ibn Sirāy, recogido en Rıus, «La alquibla en al-Andalus», p. 96. 


\section{El islam Castellano}

Las comunidades musulmanas medievales del valle del Duero, estudiadas a través de documentación escrita y arqueológica, poco a poco van siendo mejor conocidas, tanto en su realidad material como en sus relaciones económicas y comportamiento sociocultural $^{30}$.

Una de las varias cuestiones en las que se han centrado los estudios de los últimos años ha sido el acercamiento al grado de islamización que vivieron estos grupos, asentados entre los siglos XII y XV en territorio cristiano, dependiendo de la Corona, Iglesia o señoríos nobiliarios y, por tanto, al margen de la Dār al-Islām. Al riesgo de alienación cultural que supone vivir en un contexto religioso no propio, se suman las restricciones socioeconómicas que implicaron las medidas legales de apartamiento que se dictaron en el siglo Xv. Y, como otro factor a tener en cuenta, debe considerarse que estos grupos no contaban con un pasado andalusí de arraigo territorial en las ciudades en las que se asentaron, ya que estos musulmanes al norte del Sistema Central vivieron en ciudades y villas en las que, con carácter general, no se ha documentado arqueológicamente una ocupación andalusí previa ni aparecen citadas en las fuentes como enclaves andalusíes ${ }^{31}$.

A pesar de estos factores en contra, se viene demostrando que, lejos de ser unas poblaciones residuales o marginales en el contexto de la cultura islámica peninsular, crearon pequeñas comunidades en las que la práctica del islam no parece haber sufrido ninguna merma con respecto al territorio andalusí: dispusieron públicamente de mezquitas, cementerios, establecimientos y organización propia, aplicación del derecho islámico en el seno de las aljamas e incluso realizaron peregrinaciones a La Meca, de manera que el cumplimiento de los preceptos fundamentales del islam pudo materializarse claramente, de todo lo cual se están encontrando referencias documentales ${ }^{32}$. También del uso del

30 El repaso de las publicaciones y trabajos relacionados con ello de los últimos diez años es ilustrativo al respecto. Buena parte de esa bibliografía se encuentra recogida en Villanueva Zubizarreta, Olatz y Araus Ballesteros, Luis. «La identidad musulmana de los mudéjares de la Cuenca del Duero a finales de la Edad Media. Aportaciones desde la aljama de Burgos». Espacio, Tiempo y Forma. Serie III, Historia Medieval, 2014, vol. 27, pp. 525-545, [pp. 525-537], donde también se traza un amplio panorama sobre las comunidades musulmanas del valle del Duero; y en Villanueva Zubizarreta, Olatz. «De la Arqueología Mudéjar a la Arqueología Morisca: del islam permitido al islam prohibido». En Quirós Castillo, José Antonio (ed.). Treinta años de Arqueología Medieval en España. Oxford: Archaeopress Publishing Ltd, 2018, pp. 295-313, que amplían las escuetas noticias recogidas en Colominas Aparicio, Mònica. «Estudios mudéjares en el siglo veintiuno: una bibliografía seleccionada». 'Ilu. Revista de Ciencias de las Religiones, 2018, vol. 23, pp. 317-341.

31 Salvo en el caso del territorio soriano, buena parte de él, por otro lado, más vinculado al valle del Ebro. Sobre el poblamiento andalusí en el valle del Duero, Zozaya Stabel-Hansen, Juan; Larrén IzQuierdo, Hortensia; Gutiérrez González, José Avelino y Miguel Hernández, Fernando. «Asentamientos andalusíes en el Valle del Duero: el registro cerámico». Atti del IX Congresso Internazionale sulla Ceramica Medievale nel Mediterraneo. Venezia: All'Insegna del Giglio, 2012, pp. 217-229; y reflexiones en JimÉnEz GadEA, Javier. «Estelas funerarias islámicas de Ávila: clasificación e inscripciones». Espacio, Tiempo y Forma. Serie I, Nueva Época, Prehistoria y Arqueología, 2009, vol. 2, pp. 221-267 [p. 255, n. 49] y JimÉnEz GADEA, Javier. "Las monedas omeyas del Consultivo, en Zamora». Anuario del Instituto de Estudios Zamoranos Florián de Ocampo, 2016, vol. 31, pp. 29-45 [p. 41, n. 28].

32 Numerosas manifestaciones de fe islámica (escritas y arqueológicas) se recogen en VilLANUEVA Zubizarreta, Olatz. "Los mudéjares del norte de Castilla en vísperas del bautismo: expresiones religiosas de 
árabe, constatado ya fehacientemente en inscripciones de carácter religioso ${ }^{33}$, aunque al tiempo existen indicios que parecen apuntar a la formación de un castellano islamizado ${ }^{34}$, cuyo desarrollo quedó truncado por el bautismo forzoso de 1502, primero, y por la expulsión definitiva de los moriscos a comienzos del xviI, finalmente.

En este contexto, cabe preguntarse si también en estas comunidades musulmanas se encontraron con el problema de la determinación de la quibla y cómo se enfrentaron a él, con el objetivo de introducir dos elementos ańadidos al análisis histórico del islam medieval peninsular: por un lado, aportar un elemento más para comprender la verdadera naturaleza islámica de estas comunidades; $y$, por otro, aportar datos que permitan profundizar en el estudio de la quibla peninsular en la Edad Media, limitado hasta ahora, como se ha visto, a la realidad andalusí.

Es importante tener en cuenta que entre los musulmanes castellanos del territorio analizado (la cuenca del Duero), como consecuencia de su condición original de inmigrados, hubo de surgir el mismo problema con el que siglos atrás se encontraron los primeros musulmanes que llegaron a la Península Ibérica, es decir, que debieron determinar la dirección de la quibla en unas ciudades en las que no había referencia previa de ella, ex novo. Es de suponer, en consecuencia, que en un primer momento los alfaquíes que se encargaran de ello llevarían consigo el conocimiento traído desde sus inmediatos lugares de origen.

En principio, no se conoce ningún documento escrito que nos hable directamente sobre la cuestión. Cabría esperar algo, por ejemplo, en el Kitab Segoviano, escrito por el alfaquí de Segovia y alcalde mayor de los moros de Castilla, 'Īsà de Ŷābir, en la ciudad de Segovia en el año 1462, ya que se trata de un compendio o resumen de los principales preceptos que debe observar un buen musulmán para actuar en la vida de acuerdo con la Sunna o Ley islámica. Se conoce también, por ello, con el nombre de Breviario Sunní, como está escrito en el colofón del libro. Está dirigido en origen a los moros de Castilla, aunque por la importancia del autor su influencia llegó también a los territorios de la Corona de Aragón y alcanzó el siglo Xvi ${ }^{35}$.

un Islam que no fue al-Ándalus». eHumanista/Conversos 3, 2015, pp. 195-209; y desde la óptica de la cultura material, en Jiménez GAdEA, Javier. «Espacios y manifestaciones materiales de los musulmanes castellanos: presencias y ausencias de una minoría medieval». Edad Media. Revista de Historia, 2016, vol. 17, pp. 67-95. Sobre las peregrinaciones, el relato del viaje del abulense Omar Patún a La Meca en 1491 resulta revelador (Casassas Canals, Xavier; Villanueva Zubizarreta, Olatz; Tapia Sánchez, Serafín de; Jiménez Gadea, Javier y Echevarría Arsuaga, Ana. De Ávila a La Meca. El relato del viaje de Omar Patún (1491-1495). Valladolid: Universidad de Valladolid, 2017; Roza Candás, Pablo. Memorial de ida i venida hasta Maka. La peregrinación de 'Omar Pațon. Oviedo: Universidad de Oviedo, 2018).

33 JimÉnEZ GADEA, «Estelas funerarias»; «Un nuevo testimonio sobre las inscripciones árabes de Ávila, en la obra de Bartolomé Fernández Valencia». En Institución Gran Duque de Alba 1962-2012. 50 años de cultura abulense. Ávila: Institución Gran Duque de Alba, 2012, vol. I, pp. 373-388; y «Las inscripciones árabes de El Barco de Ávila». En Echevarría Arsuaga, Ana y Fábregas García, Adela (coords.). De la alquería a la aljama. Madrid: Universidad Nacional de Educación a Distancia, 2016, 195-222.

34 Cuya expresión escrita sería la aljamía árabe (Casassas Canals, Villanueva Zubizarreta, Tapia Sánchez, Jiménez Gadea y Echevarría Arsuaga, De Ávila a La Meca, pp. 61-62).

35 Wiegers, Gerard Albert. Islamic literature in Spanish and Aljamiado: Yça of Gebir (fl. 1450), his antecedents and successors. Leiden: Brill Verlag, 1994. 
Encontramos varias referencias a la alquibla en esta $\mathrm{obra}^{36}$, pero todas referidas a su utilización como dirección para realizar los actos rituales, no planteando en ningún pasaje el asunto de cómo hallar su determinación: se da por sabida. Si bien, pues, no parece ayudar mucho en el análisis que se pretende en este trabajo, sí que hay algún elemento que nos puede permitir, al menos, intuir cuál pudo ser el criterio.

De las nueve citas que he localizado, se insiste en varias de ellas en una cuestión: la de la buena voluntad, es decir, que los actos rituales que deben regirse por la orientación hacia la alquibla pueden ser incluso válidos, si se incumple este mandamiento, siempre y cuando esa circunstancia se deba a la imposibilidad o ignorancia de conocer la dirección de esta.

Así, por ejemplo, en el capítulo XI, donde se enumeran las pautas para realizar correctamente la oración (kunquwa / ntaš ikumu šákunbālā / laṣsala) [Con cuántas (cosas) y cómo se cumple la Azala] ${ }^{37}$, se dice: lašāyšanā eš dā kara alqibla i šila kunusiyārā (la sexta es de cara alquibla y si la conociera $)^{38}$.

O, en el capítulo XVI, donde se indican una serie de motivos que pueden invalidar la oración (dālaš kušaš kāata / ŷanlaṣala / kāšuntārāntā i duśs) [De las cosas que atajan la azala que son treinta y dos] ${ }^{39}$, entre ellos: el fazār nu / dā kara elalqibla aśabiyāndas ata / ýalu i turnālaṣala dā kumiyānsu (el facer [la azala] no de cara a la alquibla a sabiendas, atájelo y torne la azala de comienzo $)^{40}$; es decir, que si la oración no se dirige a la alquibla debe repetirse, siempre y cuando se haya hecho con conocimiento de causa, de lo contrario no se invalida la oración.

De estos ejemplos parece deducirse que en 'Īsà de Ŷābir hay una actitud comprensiva de las limitaciones existentes con respecto al conocimiento de la alquibla y quizá, si hacemos extensible esa actitud hacia la propia determinación de la misma, podríamos concluir que pudo imperar entre los alfaquíes castellanos el criterio de $\hat{y}$ iha frente al de samt, como en la mayoría de los malikíes en el occidente islámico.

De nuevo vuelve a apreciarse esta misma actitud flexible en el otro tratadista fundamental del islam castellano, el Mancebo de Arévalo ${ }^{41}$, quien en su Tafsira [Tratado]

36 De la cual se conservan seis manuscritos: dos en la Biblioteca Tomás Navarro Tomás del Instituto de Filología del CSIC (RESC/1, aljamiado, siglo XVI; y RESC/60, latino, siglos XVI-XVII); tres en la Biblioteca Nacional de España (MSS. 2076, latino, siglo XVI; MSS. 6016, latino, siglo XVI; MSS. 1585, latino, siglo XIX); uno en la Real Academia de la Historia, latino (RAH S3 Saa 77); y uno en el Archivo General de la Nación, México, latino (1528/54). De ellos, según Wiegers, los más cercanos al original del siglo xv son el RESC/1 y el MSS. 2076, siendo el aljamiado el que mejor respetó la ortografía original del texto (WiEgERs, Islamic literature, p. 114).

37 Manuscrito RESC/1, fol. 35r.

38 Ídem, fol. 35v.

39 Ídem, fol. $51 \mathrm{r}$.

$40 \quad$ Ídem, fol. $51 \mathrm{v}$.

41 Personaje anónimo sobre cuya identificación han existido dudas durante muchos años, un reciente trabajo de Serafín de Tapia ha puesto sobre el tablero científico la fundamentada hipótesis de que este importante escritor musulmán castellano del siglo xvi fuera un joven arevalense, que leía el Alcorán a sus correligionarios, nacido en 1502 y llamado Gutierre, hijo de Cristóbal de Barrionuevo y de Catalina Velázquez (TAPIA SÁnchez, Serafín de. "Hipótesis sobre las raíces familiares y el entorno social del Mancebo de Arévalo». Sharq al-Andalus. Estudios Mudéjares y Moriscos, 2014-2016, vol. 21, pp. 165-202). 
vuelve a realizar un trabajo similar al de 'İsà de Ŷābir, si bien ahora desde la clandestinidad y el criptoislamismo, ya que su autor nace y vive en el siglo XvI, cuando ya se ha producido, en sus propias palabras, la Kaída / de loš mmusliymes de Kaštilla y-en ešpe-/siyal de la išla del-Adaluwzziyya ${ }^{42}$.

En el capítulo primero de su Tratado, por ejemplo, al describir cómo se debe realizar la limpieza ritual de purificación previa a la oración, dice: Šea el / lugar donde te puwšiyereš el máś linpiyyo ke hallareš / i de kara el-alqibla, ši será posible ${ }^{43}$ (Sea el lugar donde te pusieres el más limpio que hallares y de cara a la alquibla, si será posible). Y más ilustrativa aún al respecto resulta la siguiente frase de su capítulo dedicado a las obligaciones, errores y enmiendas de la oración: por un lado, como no puede ser de otra manera, dice que es obligación rezar hacia la alquibla: Loš dewudos šin loš kuwaleš no še kunpele el / alș̣ala šon diyyez [...] y-el porokararše (sic) enta el-alqibla [... ${ }^{44}$ (Los deudos [obligaciones] sin los cuales no se cumple la azala son diez [...] y el procurarse [colocarse] hacia la alquibla [...]). Es decir, deja clara la obligatoriedad de rezar hacia la alquibla. Pero, líneas más adelante, reconociendo las muchas dificultades o impedimentos que la vida diaria o la ignorancia imponen para la práctica correcta de la oración, va matizando las obligaciones anteriores: Puweš todo hazedor de alșșala poro / kure hazerlo kon-akella derechura ke pueda ${ }^{45}$ (Pues todo hacedor de la azala procure hacerlo con aquella derechura que pueda). Y entre los deudos u obligaciones que pueden no cumplirse necesariamente figura: El ke hará alșsala Ifuwera de alqibla por inoransiyya, eš pašadero ${ }^{46}$ (El que hará la azala fuera de la alquibla por ignorancia, es pasadero).

Partiendo, pues, de esta actitud aparentemente flexible de los alfaquíes castellanos sobre la cuestión, veamos de qué testimonios de naturaleza material disponemos para analizar la cuestión de la alquibla en el islam medieval castellano en el valle del Duero.

\subsection{Cementerios}

En primer lugar, debemos analizar las maqbara(s) conocidas arqueológicamente, pues nos ofrecen unos datos aproximados de hacia dónde dirigían la alquibla esas comunidades, ya que el ritual islámico de enterramiento implica colocar el cadáver en posición decúbito lateral derecho, con la cabeza del difunto dirigiendo su mirada hacia La Meca. Para ello, el trazado de la fosa debe ser perpendicular a la qibla o dirección. Naturalmente, la precisión a la hora de excavar una fosa no fue ni es tan rigurosa como a la hora de erigir una mezquita, y la búsqueda de espacios libres en el cementerio hizo que la apertura de las fosas finalmente hubiera que acondicionarla, caso a caso, a la realidad existente, por

42 Nótese cómo se refiere al grupo con la expresión "muslimes de Castilla» (NArváez Córdova, M. ${ }^{a}$ Teresa (ed.). Tratado [Tafsira]. Mancebo de Arévalo. Madrid: Editorial Trotta, 2003, p. 308; fol. 292v del códice aljamiado original [manuscrito RESC/62 de la Biblioteca Tomás Navarro Tomás del Instituto de Filología del CSIC]).

43 Narváez Córdova, Tratado [Tafsira], p. 116; fol. 20r.

44 Narváez Córdova, Tratado [Tafsira], p. 124; fol. 28v.

45 Narváez Córdova, Tratado [Tafsira], p. 126; fol. 31v.

46 Narváez Cóndova, Tratado [Tafsira], p. 126; fol. 31v. 
lo que el resultado es que no todas las tumbas están orientadas exactamente igual unas a otras. Sin embargo, sí que se puede apreciar una tendencia general, que viene en muchos casos determinada por la distribución en calles de los enterramientos. En consecuencia, los datos que vamos a analizar procedentes de los cementerios deben valorarse como "tendencia», no como datos exactos. Aun así, son una primera fuente de información arqueológica de la que poder extraer conclusiones relevantes.

Conocemos tres necrópolis islámicas castellanas, fechadas entre los siglos XII y Xv: la maqbara de Santa Clara (Cuéllar, Segovia), la de la Casa de la Beneficencia (Valladolid) y la de San Nicolás (Ávila), correspondiendo la primera a una aljama de pequeño tamaño y la segunda y la tercera a unas de las más importantes de Castilla, siendo concretamente la de Auvila la más destacable y significativa ${ }^{47}$.

En el conjunto de estos enterramientos se dan básicamente dos tendencias en la orientación de las sepulturas: una que podríamos denominar tendencia sur y otra tendencia sudeste. Debido a que con carácter general en las publicaciones e informes existentes no se proporciona una orientación precisa en grados (con alguna excepción que veremos), la orientación con la que trabajaremos ha sido tomada de los planos y de las expresiones, genéricas, «orientado al sur» u «orientado al sudeste», que aparecen en la mayoría de los informes y publicaciones.

Así, en los casos de Cuéllar y Valladolid la orientación de las tumbas es siempre la misma durante toda la vida de los cementerios, que abarca desde el siglo XIII hasta el xv, para el caso de Valladolid, documentándose dos fases, y quizá algo más reciente el de Cuéllar, siglos XIV-Xv, según sus excavadores.

Se trata en ambos casos (y en Valladolid para las dos fases) de fosas trazadas en un eje E-W, de manera que la orientación de la mirada del difunto, colocado en decúbito lateral derecho con la cabeza en el extremo W de la fosa, se dirige al Sur $\left(180^{\circ}\right)$. Así se desprende

47 Para la descripción de estas necrópolis, véase JimÉnEz GADEA, «Espacios y manifestaciones», pp. 69-75, con su bibliografía correspondiente. Además de esta, para este trabajo se han consultado los informes inéditos de las correspondientes campañas de excavación, existentes en los Servicios Territoriales de Cultura y Turismo de Ávila y Valladolid, así como en el archivo del Museo de Ávila. Para la necrópolis abulense resultan especialmente útiles para el caso presente, por sus planimetrías, en un caso, y por sus mediciones, en otro, Alonso Gregorio, Óscar y Centeno Cea, Inés. La Maqbara de San Nicolás. Trabajos de excavación arqueológica en la Parcela A del Plan parcial San Nicolás 2 (Ávila). Ávila, 2006 [informe inédito] y MoredA Blanco, Javier y Serrano Noriega, Rosalía. Informe de los trabajos realizados en la necrópolis de rito islámico de San Nicolás (Ávila). IIa Fase. Ávila, 2002 [informe inédito]. La excavación de esta inmensa necrópolis (3.008 inhumaciones) se extendió en el tiempo entre 1999 y 2003, con intervenciones en seis fases. En el caso del cementerio de la Casa de la Beneficencia de Valladolid (59 inhumaciones) hubo dos intervenciones en el año 1990. Se ha consultado para este trabajo PALOMino LÁzAro, Ángel Luis y Hoyas Díez, José Luis. Informe preliminar sobre la excavación arqueológica desarrollada en el solar de la Casa de la Beneficencia. Calle de la Chancillería, núms. 12, 13 y 14 (Valladolid). Valladolid, 1990 [informe inédito]; y Herrán Martínez, José Ignacio; Santamaría González, José Enrique; Escribano Velasco, Consuelo y Balado Pachón, Arturo. Informe de la excavación arqueológica de urgencia desarrollada en el solar de la Casa de la Beneficencia (Valladolid), II campaña. Valladolid, 1990 [informe inédito]. En Cuéllar, también la maqbara de Santa Clara (134 inhumaciones) se intervino en varios momentos, en los años 1989, 1994 y 2007. Uno de los informes de esta última aporta numeroso material gráfico (Fraile Vicente, Alberto. Excavación arqueológica en la calle Barrionuevo 32 (Cuéllar, Segovia). Informe técnico de los trabajos de excavación arqueológica (junio-agosto 2007). Segovia, 2017 [informe inédito]). 
tanto de las planimetrías como de los textos de los informes y publicaciones. Por lo tanto, estaríamos ante unos casos en los que los musulmanes de estas aljamas seguían una qibla orientada hacia el mediodía. Es importante tener en cuenta que en el caso de Valladolid existió otra maqbara, más moderna, del siglo xv, no excavada arqueológicamente, pero de la que tenemos constancia documental escrita. También sabemos que el cementerio excavado arqueológicamente, el de la Casa de la Beneficencia, situado extramuros junto a la iglesia de San Pedro, recibía la denominación de «almocabyr viejo» ${ }^{48}$.

Para el caso de Ávila, la necrópolis islámica de San Nicolás también era una de las varias que tuvo la ciudad en la Edad Media ${ }^{49}$. Los datos arqueológicos proporcionados en sus excavaciones permiten establecer dos fases o momentos cronológicos en su uso, diferenciados claramente por la orientación diferente de las sepulturas. A una primera fase, que arrancaría a finales del siglo XII y llegaría hasta finales del siglo XIII/comienzos del siglo XIV, corresponden mayoritariamente sepulturas similares en su orientación a las vistas para los casos de Cuéllar y Valladolid. Es decir, fosas trazadas con carácter general de este a oeste, resultando su orientación ritual al sur. A una segunda fase, por encima de esta, y que por tanto abarcaría los siglos XIV y XV, corresponden unas sepulturas orientadas «hacia el sureste», según sus excavadores, es decir, con las fosas trazadas en un eje NE-SW.

Ya se ha comentado que en realidad esto no es más que una tendencia, puesto que no hay coincidencia absoluta entre todas las tumbas de un tipo u otro, debido a los condicionantes del espacio disponible y, sobre todo, a que sería del todo imposible conseguir una orientación absolutamente coincidente entre todas las sepulturas, habida cuenta de que cada una se abre en un momento diferente. No obstante, es significativo que en cada una de esas dos fases se siga con carácter general una de esas tendencias y que el cambio de estas se pueda asociar a un momento cronológico determinado.

Del único informe que proporciona mediciones para las orientaciones ${ }^{50}$, se extraen los siguientes datos. Para la fase más antigua, de tumbas orientadas «al sur», las orientaciones se mueven entre $175^{\circ}$ y $185^{\circ}$, mientras que las orientadas «al sudeste» lo hacen entre $150^{\circ}$ y $160^{\circ}$. A su vez, de la planimetría del informe de O. Alonso e I. Centeno, se obtienen los siguientes valores (medios): para las tumbas orientadas «al sur», del primer nivel, 190\%; para las del segundo nivel, orientadas «al sudeste», 162。.

Así, pues, vemos que en estos tres cementerios islámicos excavados arqueológicamente la orientación meridional, la más antigua en el caso de Ávila, es marcadamente sur, sobrepasando a veces los $180^{\circ}$. A su vez, la denominada «sudeste» se mueve en unos valores que se sitúan, en realidad, en un sector del cuadrante sudeste de la circunferencia mucho más cercano al sur que al este, y, por lo tanto, tiene también una marcada tendencia meridional. No obstante, el cambio es evidente y, como se ha dicho, conlleva una implicación, al menos, cronológica.

48 Jiménez GadeA, «Espacios y manifestaciones», p. 74.

49 De las otras dos, Santa Ana y Sancti Spíritus, solo tenemos noticias escritas, aunque sí se han podido identificar estelas funerarias procedentes de ellas (JIMÉnEz GADEA, «Espacios y manifestaciones», p. 73).

50 Moreda Blanco y Serrano Noriega, Informe de los trabajos realizados en la necrópolis de rito islámico. 


\subsection{Mezquitas}

En lo que respecta a las mezquitas, de las numerosas citas que aparecen en la documentación escrita castellana (normalmente citadas con la palabra almagid o sus derivados) no se han encontrado hasta ahora referencias que nos aporten información directa sobre su orientación, aunque para el caso concreto de Ávila la denominación de una de las varias que tuvo resulta especialmente significativa, como veremos.

Conservamos restos materiales de algunas de ellas, cuya identificación definitiva estaría pendiente de confirmación arqueológica, aunque ofrecen suficientes datos para el análisis de su orientación, que, eso sí, no debe ser tomada como definitiva, ya que, aunque conocemos los edificios actuales, totalmente transformados, y podemos observar su orientación o la orientación general de la parcela urbana que ocupan, no podemos afirmar con certeza absoluta dónde estuvo el muro de su quibla. Trabajaremos, pues, con hipótesis, salvo para el caso de la mezquita de Valladolid, cuya excavación arqueológica realizada entre los ańos 2018 y 2019 ha sacado a la luz los restos completos de su planta.

Se van a analizar, pues, los datos de las mezquitas de El Barco de Ávila, mezquita de la Villa (Ávila), mezquita de la Alquibla (Ávila) y mezquita de Valladolid ${ }^{51}$, que son de las que contamos con una información textual, urbanística o arqueológica que nos permite ubicarlas y relacionarlas con restos materiales existentes ${ }^{52}$.

En El Barco de Ávila, la existencia de una inscripción árabe (un takbir) en la fachada de una casa fechable en el siglo Xv -por los elementos decorativos de su portada y la documentación escrita asociada-, así como el contexto de otras inscripciones árabes en la misma calle, permiten manejar la hipótesis de que la mezquita estuviera en el solar de la C/ Mayor, 8, conservando, al menos, su portada ${ }^{53}$.

En este caso, la parcela urbana ocupada presenta una planta de tendencia rectangular, abriéndose la fachada indicada en dirección NW. Así pues, si suponemos la entrada principal en este muro, la alquibla del edificio debería ser su opuesto, resultando de ello una orientación SE. Concretamente, de la medición sobre el plano georreferenciado, que ofrece la Sede Electrónica del Catastro, se obtiene el dato de $126^{\mathrm{os}^{54}}$. Estaría, pues, orientada dentro del cuadrante E-SE.

Para Valladolid, además de la excavación arqueológica que nos ha proporcionado la planta completa del edificio (C/ Claudio Moyano, 5), contamos con abundante documentación descriptiva de la misma, que permite situar su construcción a comienzos del

51 Para su descripción y propuesta de identificación, en su caso, JimÉnEz GADEA, «Espacios y manifestaciones", pp. 77-82; Moratinos García, Manuel. Excavación de sondeos arqueológicos en el inmueble de la calle Claudio Moyano, no 5 (Valladolid). Informe técnico. La Mudarra, 2018 [informe inédito]; Palomino LÁzARo, Ángel Luis. Excavación, sondeos y control arqueológico, vinculados al proyecto de rehabilitación por restructuración parcial del edificio de viviendas situado en la C/ Claudio Moyano, no 5, Valladolid. Informe preliminar. Valladolid, 2019 [informe inédito].

52 Las mediciones ofrecidas a continuación han sido realizadas sobre el terreno con brújula y sobre planos georreferenciados, ofreciendo la media cuando se han producido ligeras discrepancias. Agradezco a Ángel Palomino el envío de un plano georreferenciado de la recién excavada mezquita de Valladolid.

53 JimÉnez GADEA, «Las inscripciones árabes», pp. 202-204 y 206-210.

54 Referencia catastral 5706204TK8750N0001GE. 
siglo Xv, cuando, como consecuencia del Ordenamiento de 1412, los musulmanes de la ciudad son obligados al apartamiento en un barrio concreto, el barrio de Santa María ${ }^{55}$. Allí deben trasladarse y allí construyen su nueva mezquita ${ }^{56}$.

En este caso, la alquibla del edificio, que conserva la huella del hueco donde se abrió el mibrab, presenta una orientación de $137^{\circ}$, situándose, pues, justo en la mitad del cuadrante SE.

En el caso de Ávila, la aljama más populosa de Castilla, aunque tenemos varias referencias de la existencia de al menos tres mezquitas ${ }^{57}$, ahora solo tomaremos en consideración dos de ellas, de las que podemos estar casi seguros de su ubicación y conservación de restos materiales, si bien muy alterados ${ }^{58}$.

El denominado almagid mayor o de la Villa estaría situado en la C/ Pocillo, $2^{59}$, en un inmueble de planta rectangular que aún conserva una característica portada del siglo XIII, de arquivoltas de piedra y ladrillo según modelos observables en otros edificios civiles y religiosos de la ciudad. Esta circunstancia, unida a su cita por primera vez en 1303, en el Libro Becerro de Visitaciones de Casas y Heredades de la Catedral de Ávila, nos lleva a remontar su existencia al siglo xiII y a considerar esta mezquita como la de los primeros musulmanes establecidos en la ciudad por entonces ${ }^{60}$.

En este caso, a diferencia de los vistos anteriormente, la orientación de la alquibla resulta claramente meridional, proporcionando un valor de $180^{\circ}$.

La otra mezquita abulense que vamos a tomar en consideración para este estudio es la denominada en los documentos archivísticos almagid de la alquibla, cuya cronología inicial debe situarse a finales del siglo xIV, encontrándola abundantemente citada en la documentación del siglo Xv. Aunque se conoce su ubicación ${ }^{61}$, actualmente se trata de un solar en ruinas, pero que aún conserva parte de las tapias y muros perimetrales que

55 Moratinos García, Manuel y Villanueva Zubizarreta, Olatz. «Consecuencias del decreto de conversión al cristianismo de 1502 en la aljama mora de Valladolid». Sharq al-Andalus. Estudios Mudéjares y Moriscos, 1999-2002, vol. 16-17, pp. 121-144.

56 Si la vieja mezquita siguió en uso o no, es cuestión aún por dilucidar. Estas mismas circunstancias deben ponerse en relación con la existencia de los dos cementerios, para los que sí tenemos constancia documental de su uso simultáneo (Villanueva Zubizarreta y Araus Ballesteros, "La identidad musulmana», p. 537).

Coincidiendo su uso en el tiempo. Sobre la importancia de Ávila en el contexto del islam castellano, Tapia SÁnchez, Serafín de. La comunidad morisca de Ávila. Salamanca-Ávila: Ediciones Universidad de Salamanca, 1991; Echevarría Arsuaga, Ana. The City of the Three Mosques: Avila and its Muslims in the Middle Ages. Wiesbaden: Reichert Verlag, 2011; Jiménez Gadea, Javier; Echevarría Arsuaga, Ana; Tapia Sánchez, Serafín de y Villanueva Zubizarreta, Olatz. La Memoria de Alá. Mudéjares y moriscos de Ávila. Valladolid: Castilla Ediciones, 2011.

58 Jiménez GadeA, «Espacios y manifestaciones», pp. 79-82.

59 Según las actuales investigaciones en curso y pendiente de publicación por parte de Serafín de Tapia y Javier Jiménez Gadea (ref. catastral 612211UL5062S).

${ }_{60}$ No obstante, hasta el siglo Xv se encuentran en la documentación escrita referencias a esta mezquita, conocida por los nombres de la Villa, Mayor o de San Esteban, lo que sugiere que pudo seguir en uso hasta entonces.

61 Manzana exenta formada por las parcelas C/Empedrada, 33 y Bajada de San Nicolás, 14 (referencia catastral 6219502UL5061N). 
pudieron pertenecer al primitivo edificio ${ }^{62}$. Entre ellos, el que sin duda debió corresponder a la quibla, que, en este caso, tiene una orientación E-SE de $123^{\circ}$.

\section{VALORACión}

Con los datos vistos hasta aquí, podemos establecer las siguientes conclusiones:

1.- En el caso de los cementerios, existe una clara discrepancia entre la orientación de los elementos más antiguos tomados en el análisis y los más modernos. Así, la fase primera del cementerio de San Nicolás de Ávila y los cementerios de Cuéllar y Valladolid, cuyo arranque se puede situar entre los siglos XII (caso de Ávila) y XIII, presenta una qibla claramente meridional, en torno a los $180^{\circ}$. Sin embargo, en la segunda fase del de Ávila (siglo Xv con claridad, quizá con arranque en el xIV) se produce una desviación hacia el E, marcando una media de $160^{\circ}$.

2.- Encontramos la misma discrepancia, con valores aún más acusados, entre las qibla(s) de las mezquitas, analizadas cronológicamente. La más antigua, el almagid mayor de Ávila, fechable en el siglo xIII, presenta una quibla de $180^{\circ}$, mientras que el resto de los ejemplos vistos, mezquita de El Barco de Ávila, Valladolid y Alquibla de Ávila, todos del siglo Xv (quizá esta última de finales del siglo XIV), están orientados hacia el cuadrante E-SE, entre los $137^{\circ}$ de Valladolid y los $123^{\circ}$ de la Alquibla abulense.

Si comparamos ahora estos datos con otros de mezquitas andalusíes, podríamos establecer las siguientes relaciones. Vemos, por ejemplo, que todas las mezquitas toledanas tienen una acusada orientación meridional. Así, los datos proporcionados por Jiménez y Rius ${ }^{63}$ otorgan a la mezquita del Solarejo (Toledo, siglo xI) un valor de $187^{\circ}$ y a la aljama de Toledo (siglo x) $180^{\circ}$. En este caso, la coincidencia (que se puede apreciar gráficamente en la figura 1) entre nuestras alquiblas castellanas más antiguas y los ejemplos toledanos puede constituir un argumento más para defender la procedencia toledana de los primeros musulmanes asentados en estos territorios ${ }^{64}$. Independientemente de si entre ellos se suscitó el problema de la orientación de la quibla en sus nuevos lugares de asentamiento, la evidencia parece indicar que se limitaron a imitar -criterio del taqlìdla que conocían de sus antepasados o de su inmediato lugar de origen, el territorio del antiguo reino de Toledo.

Por el contrario, el paso del tiempo, el surgimiento del reino nazarí y la conversión de este en el nuevo referente andalusí para todo el islam peninsular debieron ir sustituyendo la dependencia toledana por una nueva granadina. Si analizamos ahora los datos de algunas mezquitas granadinas, veremos la sorprendente coincidencia con los ejemplos castellanos de los siglos XIV-Xv. Así, la aljama de Granada (siglo xI) 141º, la aljama de

62 JimÉNeZ GADEA, «Espacios y manifestaciones», p. 80.

63 JimÉnez Martín, «La alquibla extraviada»; Rius, «La alquibla en al-Andalus».

64 En el contexto funerario, esta misma procedencia queda demostrada por la utilización de un modelo de estela funeraria, cilíndrica y vertical -el cipo-, utilizado en al-Andalus únicamente en el ámbito toledano, y localizado ahora en Castilla en Ávila y en El Barco de Ávila (JimÉnez GADEA, «Estelas funerarias», pp. 255-256; estela modelo V1, según tabla clasificatoria, p. 224). 
la Alhambra (siglo xiv) $124^{\circ}$ y el oratorio del Cuarto de Comares de la Alhambra (siglo XIV) $101^{\circ}$ [figura 1], es decir, todas en el cuadrante E-SE, y este último concretamente con la dirección exacta.

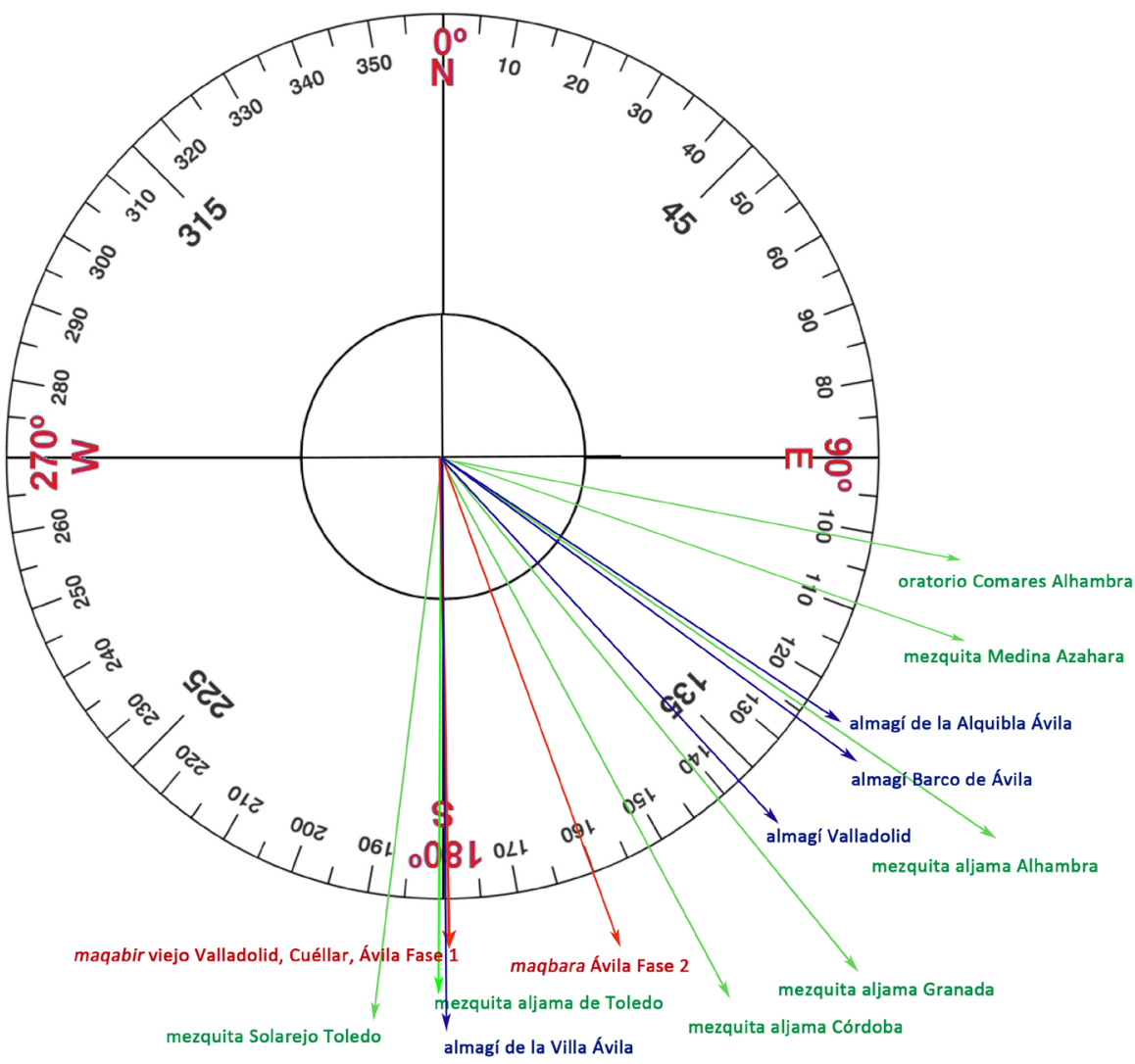

Figura 1. Gráfico comparativo entre algunas de las principales quiblas de al-Andalus y las de las mezquitas y cementerios islámicos castellanos. En verde, al-Andalus; en azul, mezquitas castellanas; en rojo, cementerios castellanos.

Si bien en Castilla no se ha documentado aún una orientación exacta hacia la $K a$ ' $b a$ similar a esta de Comares, lo cierto es que los $137^{\circ}$ de Valladolid o los $123^{\circ}$ de la Alquibla de Ávila y los $126^{\circ}$ de El Barco de Ávila claramente indican que se había cambiado el modelo con respeto a la antigua orientación meridional y que se había puesto el foco en Granada, donde a su vez y por la misma época la qibla andalusí ya tenía un rumbo diferente del cordobés (y del toledano). En este tema vemos, pues, otro ejemplo de cómo las poblaciones de musulmanes castellanos mantuvieron contactos y vínculos más allá de 
sus propias aljamas, produciéndose así un intercambio de relaciones personales, comerciales e ideológicas que conectaron el Islam peninsular a un lado y al otro de la frontera andalusí.

Sabemos de la presencia de príncipes nazaríes en Castilla (Arévalo y Segovia, por ejemplo ${ }^{65}$, de la existencia de un espacio simbólico interconectado entre musulmanes peninsulares ${ }^{66}$ y tenemos la prueba material de la aparición en el contexto del islam castellano de la utilización de la fórmula lagāliba, lema heráldico de la dinastía nazarí, en una de las estelas funerarias más ricas de Ávila, la de 'Abd Allāh ibn Yūsuf al-Ganiyy ${ }^{67}$. Y, en el caso de El Barco de Ávila, no se debe perder de vista que, aunque la presencia de musulmanes en el señorío de Valdecorneja se remonta al siglo xIV, hubo un aporte importante de población islámica traído por el I Conde de Alba y IV Señor de Valdecorneja, Fernando Álvarez de Toledo, con motivo de sus campañas militares por Andalucía en torno a $1440^{68}$.

Estas $_{\text {circulaciones }}{ }^{69}$ e intercambios sin duda debieron producir la modificación de las alquiblas castellanas, tomando como modelo las de Granada. Una Granada que, particularmente en este asunto y en esta época, protagonizó un momento de esplendor, teniendo al servicio de su mezquita aljama un equipo de muwaqqit(s), dirigido por Hasan ibn Muḥammad ibn Bāṣo, que al igual que sucedió en otras partes del mundo islámico, creó una saga familiar en torno a este oficio, siendo conocidos los Banu Bāṣo no solo como muwaqqit(s) sino también como famosos constructores de instrumentos astronó$\operatorname{micos}^{70}$.

Ávila es, por el momento, el mejor exponente de la evolución de la alquibla castellana. Los ejemplos analizados nos permiten conocer la existencia de dos orientaciones distintas, una claramente meridional y otra hacia el cuadrante E-SE, con un componente cronológico, siendo la orientación meridional la más antigua. Resulta evidente que hubo,

65 Tapia SÁnchez, «Hipótesis sobre las raíces», p. 170, donde se recoge también la tesis de L. P. Harvey de que la continuada presencia de príncipes nazaríes en Castilla pudo servir como canal de contacto entre los musulmanes castellanos y los del resto del mundo islámico.

${ }_{66}$ Expresado en la utilización común de determinados elementos para-heráldicos que, como elementos icónicos comunes, favorecerían los vínculos de conexión (JIMÉnEZ GADEA, «Las inscripciones árabes», pp. 215-220).

67 Jiménez GadeA, «Estelas funerarias», p. 229; Martínez Enamorado, Virgilio. "Lema de príncipes”. Sobre la gāliba y algunas evidencias epigráficas de su uso fuera del ámbito nazarí». Al-Qanțara, 2006, vol. 27, n. $^{\circ}$, pp. 529-550 [p. 548].

68 Luis López, Carmelo. La Comunidad de Villa y Tierra de Piedrahita en el tránsito de la Edad Media a la Moderna. Ávila: Institución Gran Duque de Alba, 1987, p. 357.

69 También sobre relaciones entre musulmanes a ambos lados de la frontera andalusí debe consultarse Echevarría Arsuaga, Ana. "De mudéjares a moriscos en el reino de Castilla (1480-1504)». Sharq al-Andalus. Estudios Mudéjares y Moriscos, 2011-2013, vol. 20, pp. 7-19; y López de Coca Castañer, José Enrique. "La emigración mudéjar al Reino de Granada en tiempos de los Reyes Católicos». En la España Medieval, 2003, vol. 26, pp. 203-226. Sobre movilidad en general de los musulmanes peninsulares, Kadri, Alice; Moreno Moreno, Yolanda y Echevarría Arsuaga, Ana (eds.). Circulaciones mudéjares y moriscas: redes de contacto y representaciones. Madrid: Consejo Superior de Investigaciones Científicas, 2018; y concluyente al respecto resulta la rihla del abulense Omar Patún (Casassas Canals, Villanueva Zubizarreta, Tapia Sánchez, Jiménez Gadea y Echevarría Arsuaga, De Ávila a La Meca).

70 SAmsó, Las ciencias de los antiguos, pp. 412-420. 
en algún momento del siglo xiv, una toma de decisión en la aljama que implicó una reorientación de la alquibla de las sepulturas y una orientación diferente para la nueva mezquita que se construyó en ese momento, siendo más acusado el cambio en el edificio que en las fosas. Y en esa decisión, seguramente tomada por un alfaquí, hubo de pesar el hecho de que el referente ideológico-cultural de los musulmanes de Ávila había pasado a ser Granada, desplazando a Toledo. Que el cambio fue un hecho consciente, que se quiso hacer notar, se demuestra en el nombre que dieron al nuevo oratorio, almagid de la Alquibla, a modo de marca de referencia de la orientación que consideraron correcta a partir de entonces.

Pero que coexistieron las dos direcciones también fue una realidad. Lo demuestra la propia coexistencia de las tres mezquitas abulenses y, muy expresamente, la referencia ya citada al uso del almoqabir viejo de Valladolid, cuyas tumbas están orientadas al sur, $180^{\circ}$, en un momento en el que su mezquita nueva lo está a $137^{\circ}$, coincidiendo prácticamente con la mezquita aljama de Granada.

En realidad, creo que se puede concluir que entre los musulmanes castellanos se reprodujeron los mismos problemas y se ofrecieron las mismas soluciones en torno a la qibla que en el mundo andalusí, circunstancia que viene a reforzar la idea de que, a pesar de que vivieron en un entorno no islámico y con fuertes restricciones socio-económicas, la práctica del islam no sufrió entre ellos ninguna merma de naturaleza sustancial, viviendo plena y conscientemente los cambios o circunstancias religiosas significativas que se produjeron en el mundo andalusí contemporáneo. En este sentido, la evolución de la dirección sagrada es un buen ejemplo de ello.

\section{REFERENCIAS BIBLIOGRÁFICAS}

Alonso Gregorio, Óscar y Centeno Cea, Inés. La Maqbara de San Nicolás. Trabajos de excavación arqueológica en la Parcela A del Plan parcial San Nicolás 2 (Ávila). Ávila, 2006 [informe inédito].

Bonine, Michael E. «The sacred direction and city structure: A preliminary analysis of the Islamic cities of Morocco». Muqarnas, 1989, vol. 7, pp. 50-72.

Bonine, Michael E. «Romans, astronomy and the qibla: urban form and orientation of Islamic cities of Tunisia». En Holbrook, Jarita C.; Medupe, Rodney Thebe y Urama, Johnson O. (eds.). African Cultural Astronomy - Current Archaeoastronomy and Ethnoastronomy Research in Africa. Berlin: Springer, 2008, pp. 145-178.

Calvo Capilla, Susana. Las mezquitas de al-Andalus. Almería: Fundación Ibn Tufayl de Estudios Árabes, 2014.

Casassas Canals, Xavier; Villanueva Zubizarreta, Olatz; Tapia Sánchez, Serafín de; Jiménez Gadea, Javier y Echevarría Arsuaga, Ana. De Ávila a La Meca. El relato del viaje de Omar Patún (1491-1495). Valladolid: Universidad de Valladolid, 2017.

Colominas Aparicio, Mònica. «Estudios mudéjares en el siglo veintiuno: una bibliografía seleccionada». 'Ilu. Revista de Ciencias de las Religiones, 2018, vol. 23, pp. 317-341.

Echevarría Arsuaga, Ana. The City of the Three Mosques: Avila and its Muslims in the Middle Ages. Wiesbaden: Reichert Verlag, 2011. 
Echevarría Arsuaga, Ana. «De mudéjares a moriscos en el reino de Castilla (1480-1504)». Sharq al-Andalus. Estudios Mudéjares y Moriscos, 2011-2013, vol. 20, pp. 7-19.

El Corán, ed. Julio Cortés. 8. a ed. Barcelona: Herder, 2002.

Fraile Vicente, Alberto. Excavación arqueológica en la calle Barrionuevo 32 (Cuéllar, Segovia). Informe técnico de los trabajos de excavación arqueológica (junio-agosto 2007). Segovia, 2017 [informe inédito].

Herrán Martínez, José Ignacio; Santamaría González, José Enrique; Escribano Velasco, Consuelo y Balado Pachón, Arturo. Informe de la excavación arqueológica de urgencia desarrollada en el solar de la Casa de la Beneficencia (Valladolid), II campaña. Valladolid, 1990 [informe inédito].

JimÉnEz GADEA, Javier. «Estelas funerarias islámicas de Ávila: clasificación e inscripciones». Espacio, Tiempo y Forma. Serie I, Nueva Época, Prehistoria y Arqueología, 2009, vol. 2, pp. 221-267.

JimÉnEZ GADEA, Javier. «Un nuevo testimonio sobre las inscripciones árabes de Ávila, en la obra de Bartolomé Fernández Valencia». En Institución Gran Duque de Alba 1962-2012. 50 años de cultura abulense. Ávila: Institución Gran Duque de Alba, 2012, vol. I, pp. 373-388.

JimÉNEZ GADEA, Javier. «Espacios y manifestaciones materiales de los musulmanes castellanos: presencias y ausencias de una minoría medieval». Edad Media. Revista de Historia, 2016, vol. 17, pp. 67-95.

JimÉnez GadeA, Javier. «Las inscripciones árabes de El Barco de Ávila». En Echevarría Arsuaga, Ana y FÁbregas García, Adela (coords.). De la alquería a la aljama. Madrid: Universidad Nacional de Educación a Distancia, 2016, 195-222.

Jiménez GadeA, Javier. «Las monedas omeyas del Consultivo, en Zamora». Anuario del Instituto de Estudios Zamoranos Florián de Ocampo, 2016, vol. 31, pp. 29-45.

Jiménez Gadea, Javier; Echevarría Arsuaga, Ana; Tapia Sánchez, Serafín de y Villanueva Zubizarreta, Olatz. La Memoria de Alá. Mudéjares y moriscos de Ávila. Valladolid: Castilla Ediciones, 2011.

Jiménez Martín, Alfonso. «La qibla extraviada». Cuadernos de Madinat al-Zahrā", 1991, vol. 3, pp. 189-209.

Kadri, Alice; Moreno Moreno, Yolanda y Echevarría Arsuaga, Ana (eds.). Circulaciones mudéjares y moriscas: redes de contacto y representaciones. Madrid: Consejo Superior de Investigaciones Científicas, 2018.

King, David A. «Kibla. II. Calcul de la Kibla». En Bosworth, Clifford E.; Van Donzel, Emeri J.; Lewis, Bernard y Pellat, Charles (eds.). Encyclopédie de l'Islam. Nouvelle édition. Leyden-Paris: Brill-Maisonneuve \& Larose, 1986, t. V, pp. 85-91.

KInG, David A. «The Orientation of Medieval Islamic Religious Architecture and Cities». Journal of the History of Astronomy, 1995, vol. 26, n. ${ }^{\circ}$ 3, pp. 253-274.

KING, David A. «The enigmatic orientation of the Great Mosque of Córdoba». Suhayl. International Journal for the History of the Exact and Natural Sciences in Islam Civilisation, 2018-2019, vol. 16-17, pp. 33-111.

López de Coca Castañer, José Enrique. «La emigración mudéjar al Reino de Granada en tiempos de los Reyes Católicos». En la España Medieval, 2003, vol. 26, pp. 203-226.

Luis López, Carmelo. La Comunidad de Villa y Tierra de Piedrahita en el tránsito de la Edad Media a la Moderna. Ávila: Institución Gran Duque de Alba, 1987.

Mālık ibn Anas. Al-Muwațta, trad. Abdurrasak Pérez, Iman Puch. Almodóvar del Río: Junta Islámica, Centro de Documentación y Publicaciones Islámicas, 1999. 
MarçaIs, George. Manuel d'Art Musulman. L'architecture. Tunisie, Algérie, Maroc, Espagne, Sicile. T. I, Du IX au XI siècle. Paris: August Picard, 1926.

Martínez Enamorado, Virgilio. "Lema de príncipes”. Sobre la gāliba y algunas evidencias epigráficas de su uso fuera del ámbito nazarí». Al-Qantara, 2006, vol. 27, n.o 2, pp. 529-550.

Moratinos García, Manuel. Excavación de sondeos arqueológicos en el inmueble de la calle Claudio Moyano, no 5 (Valladolid). Informe técnico. La Mudarra, 2018 [informe inédito].

Moratinos García, Manuel y Villanueva Zubizarreta, Olatz. "Consecuencias del decreto de conversión al cristianismo de 1502 en la aljama mora de Valladolid». Sharq al-Andalus. Estudios Mudéjares y Moriscos, 1999-2002, vol. 16-17, pp. 121-144.

Moreda Blanco, Javier y Serrano Noriega, Rosalía. Informe de los trabajos realizados en la necrópolis de rito islámico de San Nicolás (Ávila). II a Fase. Ávila, 2002 [informe inédito].

Narváez Córdova, M. ${ }^{a}$ Teresa (ed.). Tratado [Tafsira]. Mancebo de Arévalo. Madrid: Editorial Trotta, 2003.

Ocaña Jiménez, Manuel. «Arquitectos y mano de obra en la construcción de la Gran Mezquita de Occidente». Cuadernos de la Alhambra, 1986, vol. 22, pp. 55-85.

Palomino LÁzARo, Ángel Luis. Excavación, sondeos y control arqueológico, vinculados al proyecto de rehabilitación por restructuración parcial del edificio de viviendas situado en la C/ Claudio Moyano, $n^{\circ}$ 5, Valladolid. Informe preliminar. Valladolid, 2019 [informe inédito].

Palomino Lázaro, Ángel Luis y Hoyas Díez, José Luis. Informe preliminar sobre la excavación arqueológica desarrollada en el solar de la Casa de la Beneficencia. Calle de la Chancillería, núms. 12, 13 y 14 (Valladolid). Valladolid, 1990 [informe inédito].

Rıus, Mònica. «La alquibla en al-Andalus y el Magrib al-Aqșà». Anuari de Filologia. Secció B, Estudis Àrabs i Islàmics, 1998-1999, vol. 3, pp. 17-358.

Rıus, Mònica. «La alquibla: ¿ciencia religiosa o religión científica?». 'Ilu. Revista de Ciencias de las Religiones. Anejos, 2006, vol. 16, pp. 93-111.

Roza Candás, Pablo. Memorial de ida i venida hasta Maka. La peregrinación de 'Omar Pațōn. Oviedo: Universidad de Oviedo, 2018.

SAmsó, Julio. «En torno al problema de la determinación del acimut de la alquibla en al-Andalus en los siglos VIII-IX. Estado de la cuestión e hipótesis de trabajo». En Homenaje a Manuel Ocaña Jiménez. Sevilla: Junta de Andalucía, 1990, pp. 207-212.

Samsó, Julio. Las ciencias de los antiguos en al-Andalus. Madrid: Mapfre, 1992.

TAPIA SÁnchez, Serafín de. La comunidad morisca de Ávila. Salamanca-Ávila: Ediciones Universidad de Salamanca, 1991.

Tapia SÁnchez, Serafín de. «Hipótesis sobre las raíces familiares y el entorno social del Mancebo de Arévalo». Sharq al-Andalus. Estudios Mudéjares y Moriscos, 2014-2016, vol. 21, pp. 165-202.

Torres Balbás, Leopoldo. «Arte califal». En Historia de España Menéndez Pidal. Vol. 5, España musulmana: hasta la caída del califato de Córdoba (711-1031 de J. C.). Madrid: Espasa Calpe, 1957.

Vergara-Muñoz, Jaime y Martínez-Monedero, Miguel. «Las mezquitas de Arcila (Marruecos): mihrabs y quiblas». Miscelánea de Estudios Árabes y Hebraicos. Sección Árabe-Islam, 2018, vol. 67, pp. 227-245.

Villanueva Zubizarreta, Olatz. «Los mudéjares del norte de Castilla en vísperas del bautismo: expresiones religiosas de un Islam que no fue al-Ándalus». eHumanista/Conversos 3, 2015, pp. 195-209.

Villanueva Zubizarreta, Olatz. «De la Arqueología Mudéjar a la Arqueología Morisca: del islam permitido al islam prohibido». En Quirós Castillo, José Antonio (ed.). Treinta años de Arqueologia Medieval en España. Oxford: Archaeopress Publishing Ltd., 2018, pp. 295-313. 
Villanueva Zubizarreta, Olatz y Araus Ballesteros, Luis. «La identidad musulmana de los mudéjares de la Cuenca del Duero a finales de la Edad Media. Aportaciones desde la aljama de Burgos». Espacio, Tiempo y Forma. Serie III, Historia Medieval, 2014, vol. 27, pp. 525545.

Wensinck, Arent Jan. «Kibla. I». En Bosworth, Clifford E.; Van Donzel, Emeri J.; Lewis, Bernard y Pellat, Charles (eds.). Encyclopédie de l'Islam. Nouvelle édition. Leyden-Paris: Brill-Maisonneuve \& Larose, 1986, t. V, pp. 84-85.

Wiegers, Gerard Albert. Islamic literature in Spanish and Aljamiado: Yça of Gebir (fl. 1450), his antecedents and successors. Leiden: Brill Verlag, 1994.

Zozaya Stabel-Hansen, Juan; Larrén IzQuierdo, Hortensia; Gutiérrez GonZÁlez, José Avelino y Miguel Hernández, Fernando. «Asentamientos andalusíes en el Valle del Duero: el registro cerámico». Atti del IX Congresso Internazionale sulla Ceramica Medievale nel Mediterraneo. Venezia: All'Insegna del Giglio, 2012, pp. 217-229. 